\title{
On the synthesis, characterization and photocatalytic applications of nanostructured $\mathrm{TiO}_{2}$
}

\author{
P R MISHRA and O N SRIVASTAVA* \\ Department of Physics, Banaras Hindu University, Varanasi 221 005, India
}

\begin{abstract}
Nanocrystalline semiconducting materials are attracting much attention due to their potential applications in solar energy conversion, nonlinear optics, and heterogeneous photocatalysis. In the present investigation, we have synthesized nanostructured $\mathrm{TiO}_{2}$ photocatalysts, which have been used in the photocatalytic degradation of phenol (one of the most common water pollutants). These catalysts have been prepared through sol-gel technique using titanium tetra-isopropoxide as a raw material for synthesis. Characterization techniques such as XRD, SEM and TEM have been employed for structural/microstructural investigations. XRD results show that the as synthesized $\mathrm{TiO}_{2}$ nanopowder exhibit anatase phase, $\mathrm{TiO}_{2}$. The average sizes of the $\mathrm{TiO}_{2}$ nanopowders are $\sim 5-10 \mathrm{~nm}$. The optical properties of the samples were investigated through UVvisible and fluorescence techniques. It has been observed that absorption edge corresponds to $\sim 410 \mathrm{~nm}$ (bandgap, $\sim 3.02 \mathrm{eV}$ ). The emission peak in the fluorescence spectrum at $\sim 418 \mathrm{~nm}$ corresponds to the bandgap energy of $\sim 2.97 \mathrm{eV}$. Concentration of phenol (initial concentration, $\sim 100 \mathrm{ppm}$ ) with illumination time was monitored by measuring the absorbance of pure and illuminated phenol through UV-visible spectrophotometer. Salient feature of this study relates to the fact that the present sol-gel synthesized $\mathrm{TiO}_{2}$ nanopowders have been found to be better photocatalysts for phenol degradation than the presently employed commercial $\mathrm{TiO}_{2}(\mathrm{P}-25$, Degussa) photocatalyst. Thus, whereas phenol concentration, with the presently synthesized $\mathrm{TiO}_{2}$ nanopowders, the concentration of phenol decreases up to $\sim 32 \%$ but for commercial $\mathrm{TiO}_{2}$ nanopowder $(\mathrm{P}-\mathbf{2 5}$, Degussa), it decreased only up to $\sim 25 \%$. The improved surface area is considered as an important factor for the aforesaid decrease in phenol concentration.
\end{abstract}

Keywords. Sol-gel method; nanostructured $\mathrm{TiO}_{2}$; P-25 Degussa; photocatalytic degradation.

\section{Introduction}

Photocatalytic effects of the semiconductors have been of much interest from the viewpoint of solar energy utilization. They have been used to convert pollutants present in the waste streams to innocuous products (Kutal and Serpone 1993; Junge and Grange 2000; Yuan et al 2002; Srinivasan et al 2006). The fact, that among the other common water pollutants, the organic pollutants such as phenol undergoes photocatalytic degradation to produce less harmful products, indicates some potential for photocatalytic treatments of waste water utilizing semiconductor and sunlight. Phenol is a refractory and also a common compound present in the industrial wastes. The photocatalytic decomposition of phenol is one of the attractive methods which utilizes solar energy and a semiconductor photocatalyst. The decomposition process of phenol generally obeys the first order reaction kinetics (Kawaguchi and Vejima 1983). The photocatalytic decomposition of phenol has not, however, been clarified in detail yet. Photocatalytic decomposition of phenol present in water is a straightforward process for lowering the concentration of phenol to safe limit.

*Author for correspondence (hepons@yahoo.com)
Titanium dioxide $\left(\mathrm{TiO}_{2}\right)$ offers a great potential as a catalyst material for its use in the industrial technology for detoxifying wastewater (Kutal and Serpone 1993) and it has been widely investigated as a key material for applications in photovoltaic cells, batteries, chemical sensing (Varghese et al 2003), optical emissions, photonic crystals, catalysis, photocatalysis (Livraghi et al 2005) and environmental purification (Homyara et al 2001). Anatase $\mathrm{TiO}_{2}$ electrodes are used in solar cells, lithium batteries and electrochromic devices (Hagfeldt and Gratzel 1995; Kavan et al 2000; Gratzel 2001). Non-toxicity, environmental compatibility and low prices are the other practical advantages of $\mathrm{TiO}_{2}$. As a catalyst and/or catalyst support, it is employed in the processes of photo degradation of chlorine hydrocarbons. Anatase phase of $\mathrm{TiO}_{2}$ is important because of its higher Fermi level, lower capacity to absorb oxygen and higher degree of hydroxylation (i.e. number of hydroxy groups on the surface) (Maruska and Glesh 1978; Gerischer and Heller 1992).

Nanocrystalline materials are attracting much attention due to their increasing applications in the solar energy conversion, nonlinear optics and heterogeneous catalysis. Recently, efforts have been made to obtain nanostructured $\mathrm{TiO}_{2}$-based materials with large specific surface area. The energy band structure and photophysical, pho- 
tochemical and surface properties for nanostructured $\mathrm{TiO}_{2}$ are quite different than those of its bulk counterparts due to the quantum size effect.

A variety of methods have been developed so far for the synthesis of $\mathrm{TiO}_{2}$ nanoparticle, for example, d.c. magnetron sputtering (Loebl et al 1994), hydrothermal (Wu et al 2002; Cozzoli et al 2003), solvothermal method (Kim et al 2003) and emulsion precipitation. In addition, an attractive method for the preparation of nanostructured $\mathrm{TiO}_{2}$, is sol-gel method (Wilke and Breuer 1999; Francisco and Mastelaro 2002; Frindell et al 2002). It is known that the efficiency of $\mathrm{TiO}_{2}$ as a catalyst is higher when it consists of a single phase in the anatase form (Francisco and Mastelaro 2002; Diebold 2003).

Keeping the above aspects in view, we report in this paper the synthesis of a single phase, ultra fine nanostructured $\mathrm{TiO}_{2}$ photocatalyst through cost effective sol-gel technique using titanium tetra-isopropoxide as a precursor material. The composition and crystallinity of these structures have been determined by transmission electron microscopy (TEM) and scanning electron microscopy (SEM). The optical absorption spectra of the as synthesized $\mathrm{TiO}_{2}$ powders have been investigated through UVvisible and photoluminescence techniques. The photocatalytic degradation of phenol has been studied with both the photocatalyst in the reactor fabricated with a quartz tube with a fused silica tube inlet for purging oxygen during illumination (light intensity being $\sim 85 \mathrm{mWcm}^{-2}$ ) and an outlet for the collection of phenol solution. The concentration of phenol before and after illumination has been monitored by measuring the absorbance of phenol solution through UV-visible spectrophotometer (Varian, Make USA).

\section{Experimental}

\subsection{Preparation of $\mathrm{TiO}_{2}$ photocatalyst}

The sol (nearly transparent) of $\mathrm{TiO}_{2}$ was prepared by mixing titanium iso-propoxide, $\mathrm{Ti}\left[\mathrm{OC}_{3} \mathrm{H}_{7}\right]_{4}$ in iso-propanol (solvent). Water $\left(\mathrm{H}_{2} \mathrm{O}\right)$ and acetic acid $\left(\mathrm{CH}_{3} \mathrm{COOH}\right)$ were added to the above solution for hydrolysis polycondensation reaction, where the acetic acid was used as a chelating agent. The composition for the synthesis of $\mathrm{TiO}_{2}$ sol (stock solution) was $\mathrm{Ti}\left[\mathrm{OC}_{3} \mathrm{H}_{7}\right]_{4} / \mathrm{CH}_{3}-\mathrm{CH}_{2}-$ $\mathrm{OH} / \mathrm{H}_{2} \mathrm{O} / \mathrm{CH}_{3} \mathrm{COOH}-12: 10: 150: 5$ in volumetric ratio. The above solution was heated at $\sim 80^{\circ} \mathrm{C}$ for $\sim 5 \mathrm{~h}$ with vigorous stirring. When the solution becomes semitransparent, nearly $1 \mathrm{~mL}$ of $\sim 70 \% \mathrm{HNO}_{3}$ was added to the above solution in order to prevent the agglomeration of the particles present in the sol. The stirring was continued for $\sim 2 \mathrm{~h}$ and a transparent solution was obtained. This solution was then concentrated in vacuum until a viscous sol was obtained. This sol was dried in the oven at $\sim 100^{\circ} \mathrm{C}$ for $\sim 12 \mathrm{~h}$. The powder was derived by drying the above viscous sol at $\sim 100^{\circ} \mathrm{C}$ for nearly $5 \mathrm{~h}$. This powder was then calcined at $\sim 450^{\circ} \mathrm{C}$ for $\sim 2 \mathrm{~h}$ in order to improve the crystallinity of the powder samples.

It should be pointed out that the synthesis of pure $\mathrm{TiO}_{2}$ in the present investigation was focused on preparation of suitable $\mathrm{TiO}_{2}$ nanopowder for use in phenol degradation. There have been other studies on the synthesis of doped $\mathrm{TiO}_{2}$ nanopowders aimed at preparation and characterization of their doped versions (Francisco and Mastelaro 2002; Frindell et al 2002).

\subsection{Photocatalytic measurements}

The photocatalytic measurements were carried out in a reactor consisting of a quartz tube having its diameter, $\sim 3 \mathrm{~cm}$, with an inlet tube for oxygen purging during photocatalysis and another outlet for the collection of samples from the reactor at different time intervals. Initially $\sim 2.5 \mathrm{~g}$ of as synthesized nanostructured and the same amount of commercial $\mathrm{TiO}_{2}$ (P-25, Degussa) photocatalyst in $\sim 400 \mathrm{cc}$ of $\sim 100 \mathrm{ppm}$ phenol solution was taken. Phenol solution ( $\sim 400 \mathrm{ml}$ by volume) was prepared by dissolving phenol crystals in double distilled water. During illumination, oxygen gas was purged into the solution with the help of porous fused silica tube by an external cylinder. Oxygen was bubbled through this solution at a rate of $\sim 200 \mathrm{cc} / \mathrm{min}$. During the reaction, solution was maintained at $25^{\circ} \mathrm{C}$ and $\sim 3 \mathrm{cc}$ of the samples was collected at given time intervals e.g. $10 \mathrm{~min}$. After being sampled, the suspension was centrifuged and the centrifugates were subjected to further analysis. The schematic diagram of the fabricated photocatalytic reactor along with the other related accessories are given in figure 1.

\section{Results and discussion}

\subsection{Structural and microstructural characterizations}

Figure 2 represents the XRD pattern of $\mathrm{TiO}_{2}$ powders obtained through sol-gel method. The XRD (X-Pert PRO, PANalytical) pattern of the as-prepared $\mathrm{TiO}_{2}$ showed the presence of very broad peaks. The broad peaks indicate either the $\mathrm{TiO}_{2}$ nanopowder containing particles of very small crystallite size or particles which are semicrystalline in nature (Yeha et al 2004). All the diffraction lines have been found to correspond to anatase crystalline phase of titanium dioxide. It should be noted that only anatase $\mathrm{TiO}_{2}$ can be detected and no rutile phases have been found for these $\mathrm{TiO}_{2}$ powder samples. This can be attributed to the contribution of the low concentration of oxygen vacancies hindering the transformation of anatase to rutile phase (Rulison et al 1996). As it has been mentioned the efficiency of the $\mathrm{TiO}_{2}$ as a catalyst is higher when it consists of a single phase (anatase phase) (Francisco and Mastelaro 2002; Diebold 2003). The $\mathrm{TiO}_{2}$ 
which has been synthesized in the present investigation consists of only anatase phase, hence, it can act more effectively as a catalyst.

Figure 3(a and b) shows the SEM (Philips, XL-20) micrograph of the $\mathrm{TiO}_{2}$ powder samples. It is clear that very fine particles of $\mathrm{TiO}_{2}$ are joined with each other forming the cluster of particles. It appears from the SEM micrograph that the average crystallite size of pure $\mathrm{TiO}_{2}$ are in the range of $\sim 40-50 \mathrm{~nm}$. The TEM (Tecnai G20, $200 \mathrm{kV}$ ) images and corresponding selected area electron diffraction patterns of the $\mathrm{TiO}_{2}$ powder has been shown in figure 4(a and $b)$. This micrograph reveals that the nanopowder consists of very fine particles corresponding to only anatase phase of $\mathrm{TiO}_{2}$.

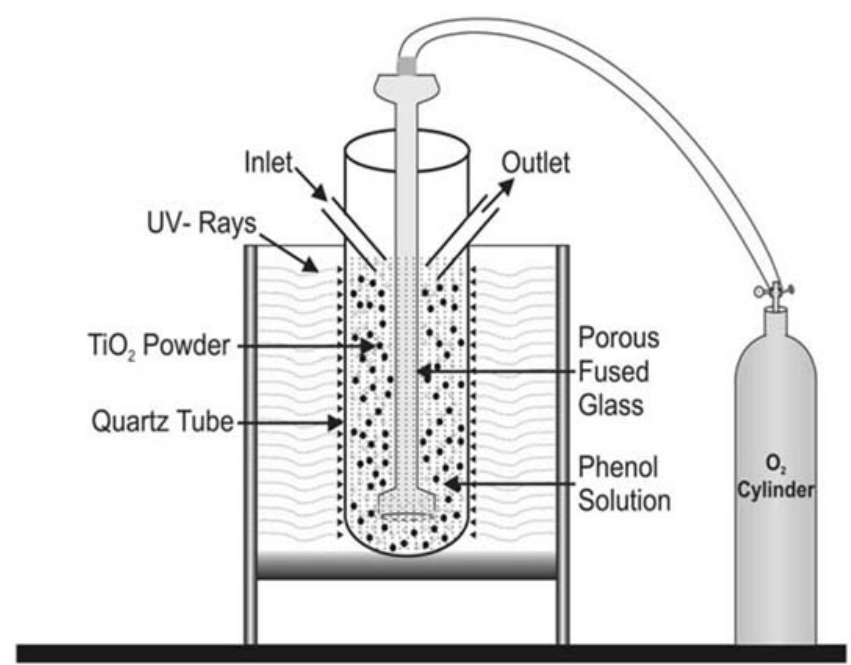

Figure 1. Schematic diagram of the fabricated photocatalytic reactor.

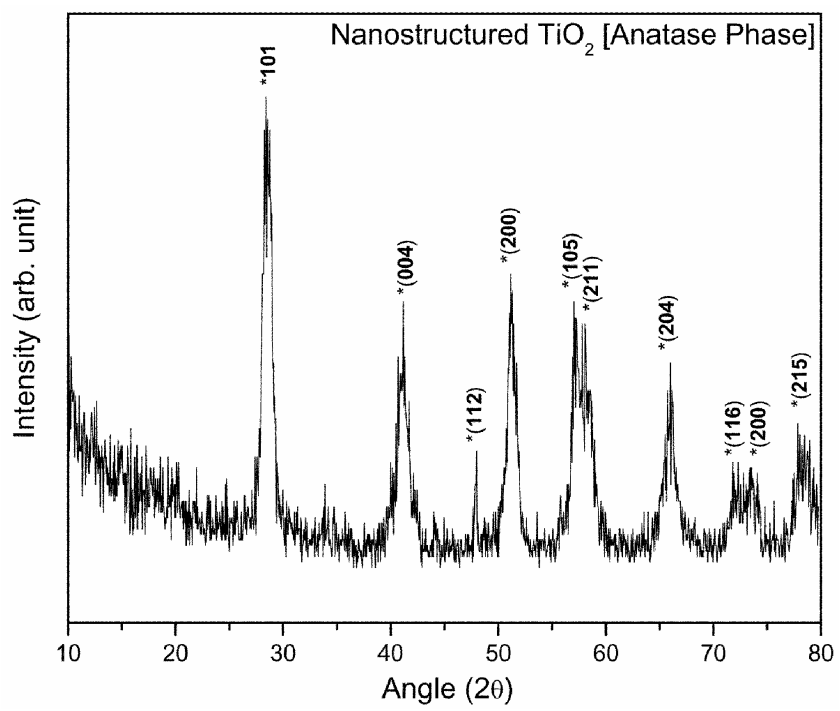

Figure 2. XRD pattern of $\mathrm{TiO}_{2}$ photocatalyst prepared through sol-gel method.

\subsection{Optical characterization}

UV-visible absorption spectrum was carried out in order to characterize the optical absorbance of the $\mathrm{TiO}_{2}$ nanopowder. The absorption spectrum of pure $\mathrm{TiO}_{2}$ is shown in figure 5 with a value of the absorption edge at $\sim 410 \mathrm{~nm}$. Due to the improved grain size for modified $\mathrm{TiO}_{2}$ photocatalyst, the absorption edge undergoes a red-shift to some extent. The optical bandgap energy can be estimated by using the following equation for a semiconductor

$$
\alpha=\left[\frac{\left(K(h v-E g)^{n / 2}\right.}{h v}\right],
$$

where $\alpha$ is the absorption coefficient, $K$ a constant, $E g$ the bandgap, and $n$ is equal to 1 for a direct transition. The bandgap can be estimated from a plot of $(\alpha h v)^{2}$ vs photon energy $(h v)$. The intercept of the tangent to the plot will give a good approximation of the bandgap energy for this direct bandgap material (shown in the inset of figure 5) (Wang and Herron 1991). The bandgap of the $\mathrm{TiO}_{2}$ powder was calculated to be $\sim 3.02 \mathrm{eV}$.
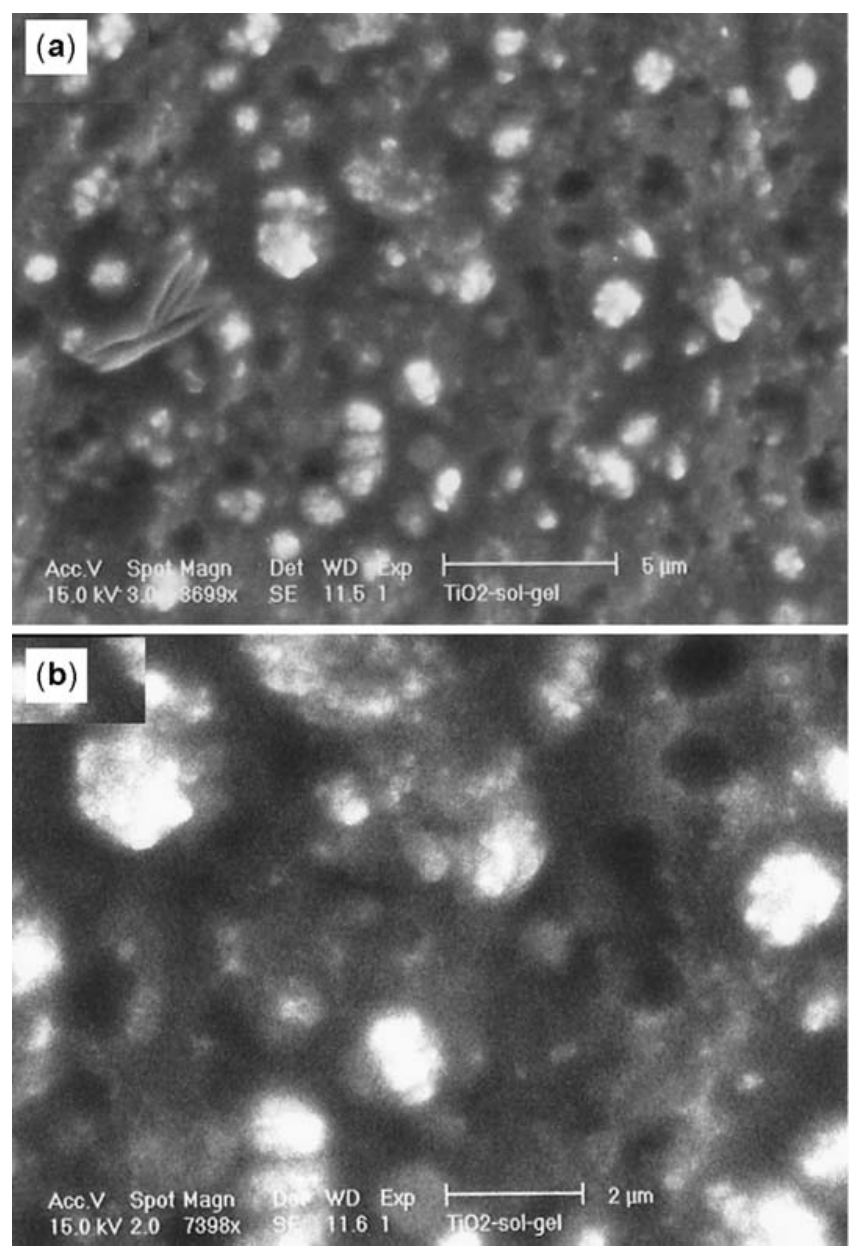

Figure 3. (a\&b). SEM images of nanostructured $\mathrm{TiO}_{2}$ photocatalysts. 
Fluorescence spectra were recorded at room temperature on the $\mathrm{TiO}_{2}$ photocatalysts with the excitation wavelength, $350 \mathrm{~nm}$ and has been shown in figure 6 . This spectrum possesses peaks at $\sim 418$ for pure $\mathrm{TiO}_{2}$ samples. In this case, the band peaking at $427 \mathrm{~nm}$ can be ascribed to electron transition mediated by defects levels in the bandgap such as oxygen vacancies formed during sample preparation (Vanheusden et al 1996). Oxygen vacancies have been considered as the most common defects and usually act as radiative centres in luminescence processes ( $\mathrm{Gu}$ et al 2004). In the present case, due to $\mathrm{TiO}_{2}$ nanostructures with high surface-to-volume ratio, favour the existence of large quantities of oxygen vacancies. The peak positions in the corresponding fluorescence spectrum represent the bandgap energy of $\mathrm{TiO}_{2}$ powder photocatalyst. It may be noted that these peaks correspond to the bandgap energy of $\sim 2.97 \mathrm{eV}$. These results are quite consistent
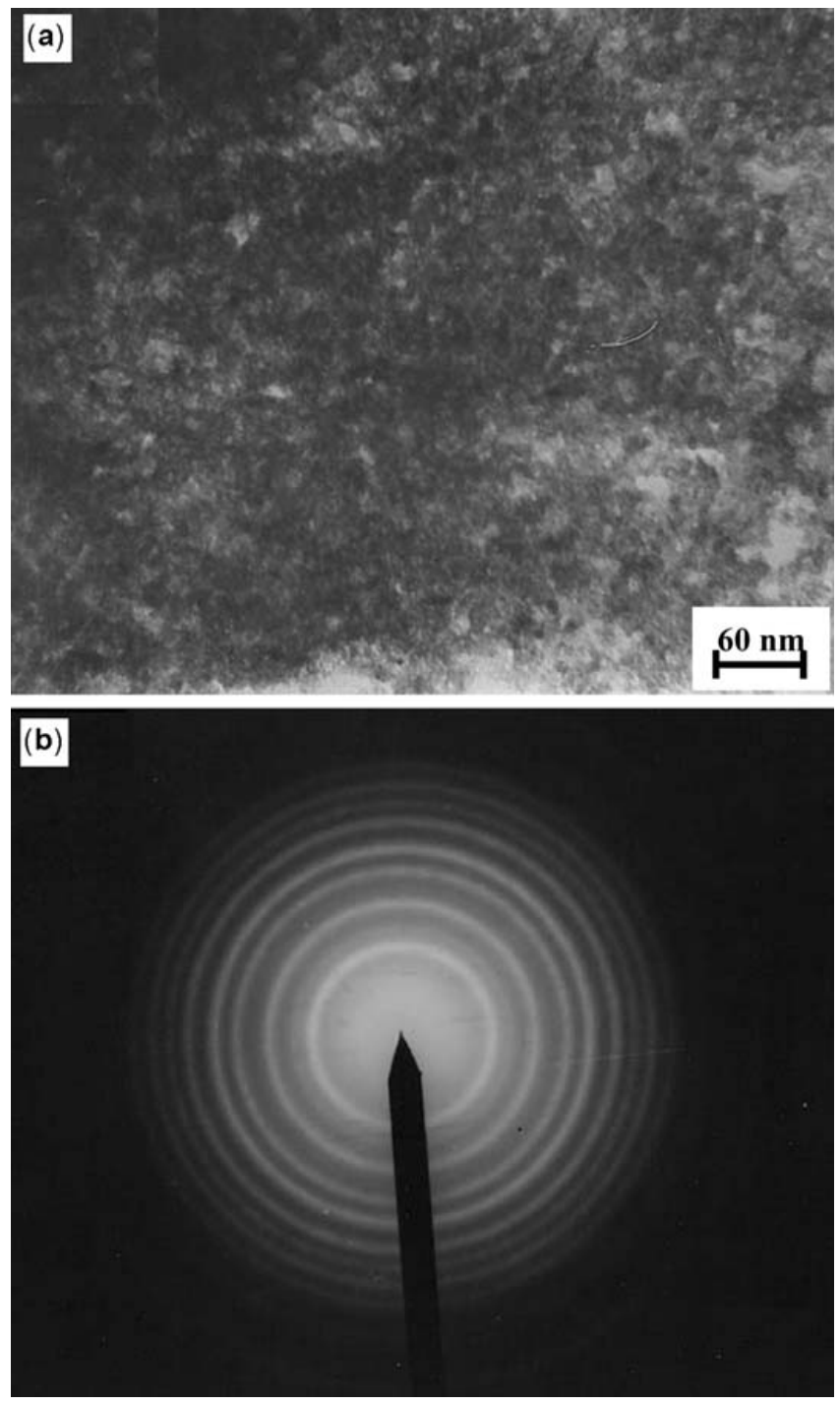

Figure 4. (a\&b). TEM image and corresponding electron diffraction pattern of nanostructured $\mathrm{TiO}_{2}$ photocatalyst. with the bandgap energy calculated by UV measurements techniques (i.e. $\sim 3.02 \mathrm{eV}$ ).

\subsection{Results on photocatalytic degradation of phenol in water}

The photocatalytic analysis using UV-vis light irradiation of phenol in the aqueous solution was examined in the photocatalytic reactor as shown in figure 1. UV-light was made to fall on the reactor through the tube walls. To determine the concentration of phenol in the solution, samples were collected after every 10 min interval upon $\mathrm{UV}$-induced degradation of phenol. The concentration of

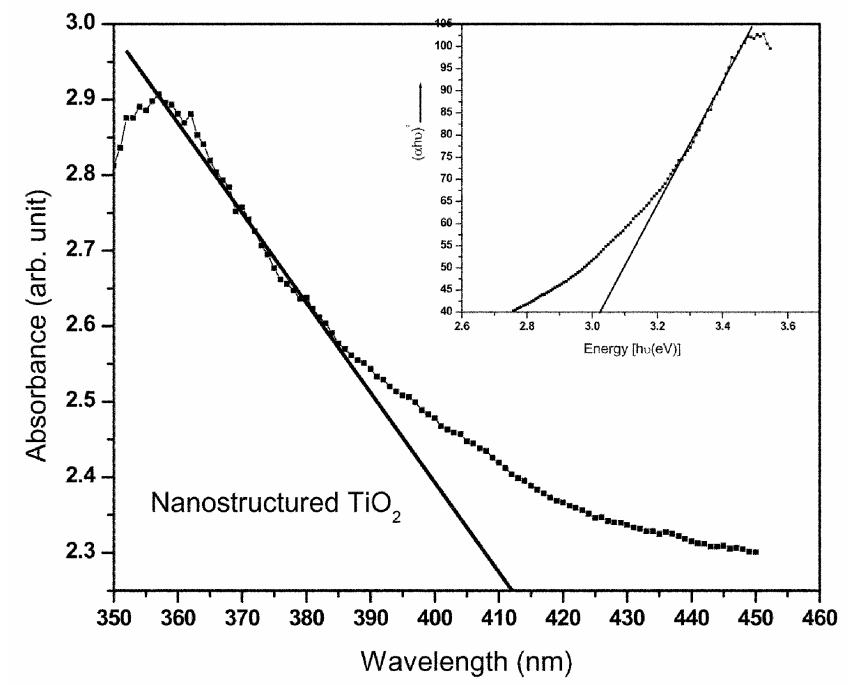

Figure 5. Absorption spectrum of nanostructured $\mathrm{TiO}_{2}$ photocatalyst powder. Inset shows the corresponding plot of $(\alpha h v)^{2}$ vs photon energy of the sample.

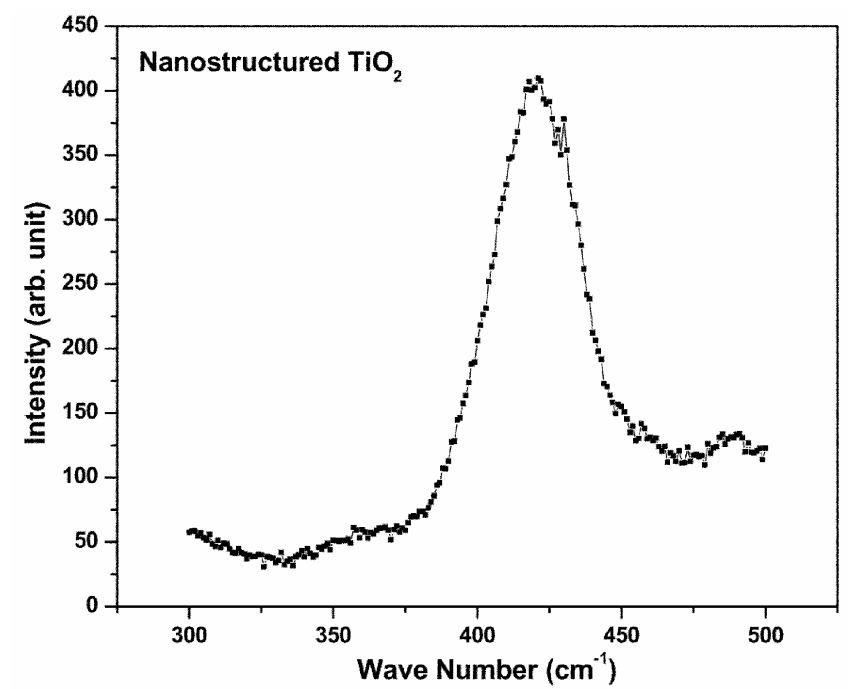

Figure 6. Fluorescence spectra of nanostructured $\mathrm{TiO}_{2}$ powder. The excitation wavelength is $350 \mathrm{~nm}$. 


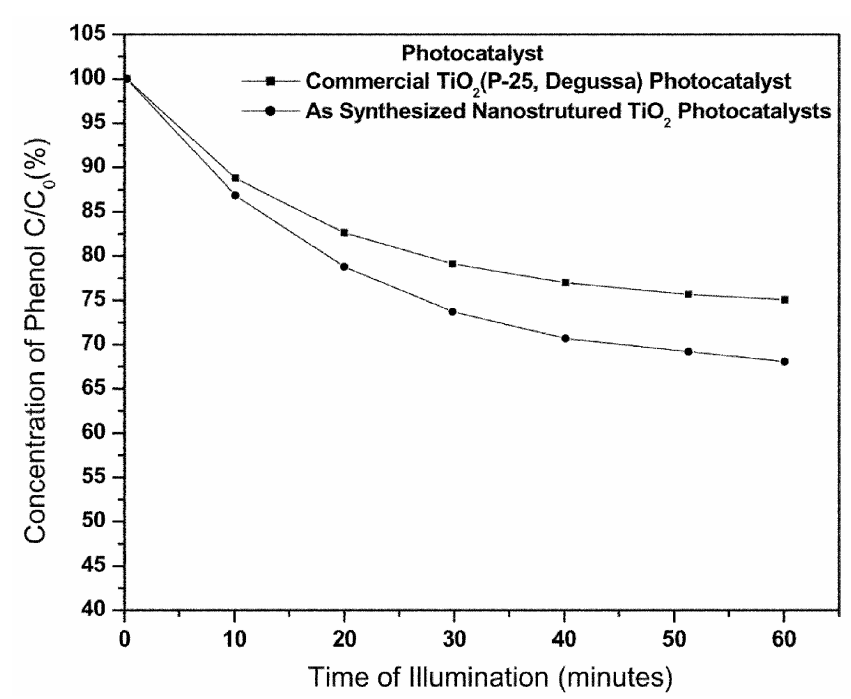

Figure 7. Variation of concentration of phenol with irradiation time using as synthesized nanostructured $\mathrm{TiO}_{2}$ and commercial $\mathrm{TiO}_{2}$ (P-25, Degussa) photocatalyst. (The excitation wavelength is $\sim 269 \mathrm{~nm}$ ).

phenol was determined by UV-visible absorption spectroscopic technique, where the absorbance was measured at a fixed wavelength (e.g. $\sim 269 \mathrm{~nm}$ ) for all the samples. Possible mechanism for photocatalytic degradation of phenol using nanostructured $\mathrm{TiO}_{2}$ films as photocatalyst has been described by us (Srivastava et al 2005).

Variation of phenol concentration using $\mathrm{TiO}_{2}$ photocatalysts after irradiation as a function of time have been shown in figure 7 . It can be seen that the concentration of the phenol decreases from $100 \%$ (initial concentration of phenol, $\sim 100 \mathrm{ppm}$ ) to $\sim 68 \%$ (final concentration of phenol, $\sim 68 \mathrm{ppm}$ ) after $\sim 1 \mathrm{~h}$ illumination. The total decrease in the phenol concentration using nanostructured $\mathrm{TiO}_{2}$ synthesized in the present investigation is $\sim 32 \%$, which is nearly the safe limit of the phenol concentration in the solution. On the other hand, the decrease in phenol concentration employing commercial $\mathrm{TiO}_{2}$ nanopowder $(\mathrm{P}$ 25 , Degussa), is only $\sim 25 \%$. Thus the $\mathrm{TiO}_{2}$ nanopowder prepared in the present investigation is more effective than the degradation of phenol through the commercial $\mathrm{TiO}_{2}$ nanopowder. Also analysis of water after photocatalytic degradation showed that no other compounds including any toxic components get formed. Thus the only effect of photocatalytic reaction is the dissociation of phenol.

\section{Conclusions}

Based on the above results, it can be concluded that ultrafine nanostructured $\mathrm{TiO}_{2}$ photocatalysts have been synthesized through a cost effective (i.e. sol-gel) technique. $\mathrm{XRD}$ results show that the as synthesized $\mathrm{TiO}_{2}$ photocatalysts consist of a single phase $\mathrm{TiO}_{2}$ nanopowder (i.e. anatase phase). SEM and TEM investigations revealed that the average sizes of the $\mathrm{TiO}_{2}$ particles are fine and are in the nanometric range. Optical characterizations revealed that the bandgap of the as synthesized $\mathrm{TiO}_{2}$ photocatalysts are $\sim 3.02 \mathrm{eV}$. The emission peak in the fluorescence spectrum at $\sim 418 \mathrm{~nm}$ corresponds to the bandgap energy, $\sim 2.97 \mathrm{eV}$. Concentration of phenol (initial concentration, $\sim 100 \mathrm{ppm}$ ) with illumination time was monitored for the as synthesized $\mathrm{TiO}_{2}$ and commercial $\mathrm{TiO}_{2}$ (P-25, Degussa) photocatalysts and it was found that the decrease in the phenol concentration was significant for the as synthesized $\mathrm{TiO}_{2}$ photocatalysts $(\sim 32 \%)$, whereas for the commercial $\mathrm{TiO}_{2}$ (P-25, Degussa) photocatalysts, the decrease in phenol concentration was only $\sim 25 \%$.

\section{Acknowledgements}

The authors are extremely grateful to Prof. A R Verma and Prof. C N R Rao (FRS, Chairman, Nanoscience and Technology, Govt. of India). The experimental facilities (such as UV-vis and fluorescence spectrophotometer) provided by Prof. A S K Sinha, Chemical Engineering Department, Banaras Hindu University, Varanasi, is gratefully acknowledged. The authors acknowledge with gratitude the financial support from DST (UNANST: $\mathrm{BHU})$. One of the authors (PRM) is thankful to MNRE, Government of India, for awarding a National Renewable Energy (NRE) Fellowship to carry out his research work.

\section{References}

Cozzoli P D, Kornowski A and Weller H 2003 J. Am. Chem. Soc. 12514539

Diebold U 2003 Surf. Sci. Rep. 4853

Francisco M S P and Mastelaro V R 2002 Chem. Mater. 14 2514

Frindell K L, Bartl M H, Popitsch A and Stucky G D 2002 Angew. Chem. Int. Ed. 41960

Gerischer H and Heller A 1992 J. Electrochem. Soc. 139113

Gratzel M 2001 Nature 414338

Gu F, Wang S F, Lu M K, Zhou G J, Xu D and Yuan D R 2004 J. Phys. Chem. B108 8119

Hagfeldt A and Gratzel M 1995 Chem. Rev. 9549

Homyara Het al 2001 Thin Solid Films 386173

Junge S M and Grange P 2000 Catal. Today 59305

Kavan L, Attia A, Lenzmann F, Elder S H and Gratzel M 2000 J. Electrochem. Soc. 1472897

Kawaguchi H and Vejima T 1983 Kagakukogaku Ronbunshu 9 107

Kim C S, Moon B K, Park J H, Choi B C and Seo H J 2003 J. Cryst. Growth 257309

Kutal C and Serpone N 1993 Photosensitive metal organic systems: Mechanistic principles and applications (Washington DC: American Chemical Society)

Livraghi S, Votta A, Paganini M C and Giamello E 2005 Chem. Commun. 4498

Loebl P, Huppertz M and Mergel D 1994 Thin Solid Films 251 
Maruska H P and Glesh A K 1978 Solar Energy 20343

Rulison A J, Miquel P F and Katz J L 1996 J. Mater. Res. 12 3083

Srinivasan S S, Wade J, Stefanakos E K and Goswami Y 2006 J. Alloys Compd. 424322

Srivastava O N, Srivastava A, Dash D, Singh D P, Yadav R M, Mishra P R and Singh J 2005 Pramana-J. Phys. 65581

Vanheusden K, Warren W L, Seager C H, Tallant D R, Voigt J A and Gnade B E 1996 J. Appl. Phys. 797983
Varghese O K, Gong D W, Paulose M, Ong K G, Dickey E C and Grimes C A 2003 Adv. Mater. 15624

Wang Y and Herron N 1991 J. Phys. Chem. 95525

Wilke K and Breuer H D 1999 J. Photochem. Photobiol. A121 49

Wu M, Lin G, Wang G, He D, Feng S and Xu R 2002 Chem. Mater. 141974

Yeha C L, Yeh S H and Ma H K 2004 Powder Technol. 1451

Yuan Z, Jia J and Zhang L 2002 Mater. Chem. Phys. 73323 